\title{
Childbearing History and Self-Reported Well-Being in Later Life
}

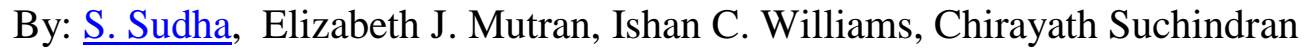

Sudha, S., Mutran, E. J., Williams, I. C., Suchindran, C. (2006). Childbearing history and later life health: Contrasting older African American and White women. Research on Aging 28(5) pp 599-621.

Made available courtesy of Sage Publications: $\underline{\text { http://roa.sagepub.com/content/28/5/599 }}$

\begin{abstract}
*** Reprinted with permission. No further reproduction is authorized without written permission from Sage Publications. This version of the document is not the version of record. Figures and/or pictures may be missing from this format of the document. ***
\end{abstract}

\begin{abstract}
:
The authors examined how numbers of live births and pregnancy losses affected the self-rated health and depressive symptoms of women aged 50 years and older, contrasting African Americans and Whites. The authors used data from Atherosclerosis Risk in Communities, a large, prospective study with substantial minority representation. They tested hypotheses that childbearing history variables would influence self-rated well-being among older women and that perceived social support would mediate the associations. The authors also tested whether these associations would be stronger among older African American versus White women. The results suggest that the impact of childbearing history is greater among older African American than White women. Pregnancy loss worsened depressive symptoms and self-rated health among African American women; the effect was reduced by social-support variables. High parity was associated with worse self-rated health among African American women, mediated by social support. Having no live births was not associated with diminished well-being among older women of any race.
\end{abstract}

Keywords: race | ethnicity | older women | self-reported health | depressive symptoms | childbearing history

\section{Article:}

Research highlights how various earlier-life factors, ranging from intrauterine conditions to experiences in childhood or young adulthood, influence health outcomes later in life (e.g., Blackwell, Hayward, and Crimmins 2001; Cameron and Demerath 2002). We add to these efforts by examining the impact of childbearing history on women's self-reported health in later life, because of the importance of motherhood as a key role and source of status in the lives of women. Prior studies on this association have indicated its importance but presented mixed evidence. On one hand, Kington, Lillard, and Rogowski (1997) illustrated that high parity (more than six children) and infant death are related to lower self-reported general health and functional status, net of socioeconomic status and related health conditions, among women aged 50 years and older. On the other hand, Zhang and Hayward (2001) demonstrated that childlessness is not related to depressive symptoms among older women. As the U.S. population grows older and 
more ethnically diverse, and different cohorts with widely varying childbearing histories age, more evidence on this issue is needed. Most prior studies controlled for race and ethnicity but did not explicitly consider how associations differ among different groups. Additional studies would clarify diverse findings and help identify factors that place seniors at risk for lowered well-being.

We examined the relation between variations in childbearing experience and self-reported wellbeing among older women, in particular contrasting associations among community-dwelling African American and White women. We examined first how variations in childbearing history influence the self-reported well-being of older women (controlling for age, socioeconomic status and chronic physical health conditions) and second whether social support mediates the associations. The outcomes we examined were self-rated health and self-reported depressive symptoms. The indicators of childbearing history included variations in the numbers of children born live and pregnancy losses. These are key factors in the experience of motherhood but have rarely been examined for their impact on later-life well-being.

The importance of these two outcomes is widely established. Self-rated health, cross-culturally and cross-nationally, is a consistently significant predictor of future health, functional status, and mortality among older populations (see reviews in Benyamini and Idler 1999; Idler and Benyamini 1997). Self-reported depressive symptomatology in a nonclinical population is also a major health concern for seniors. Although distinct from clinical depression because it is not a confirmed medical diagnosis, it is highly correlated with clinical depression and established as a key indicator of psychosocial well-being, associated with various physical comorbidities and the risk of suicide.

\section{Impact of Variations in Childbearing History on Well-Being of Older Women: Prior Findings}

The aspects of childbearing history we considered in this study included bearing no children, bearing a large number of children, and experiencing pregnancy loss. The impact of childlessness in particular on depressive symptoms among seniors has been much examined, particularly because the proportion of childless American seniors is growing. Research has highlighted the paradox that although seniors without children report lower levels of social support and greater social isolation compared with their peers with children, psychological wellbeing does not differ between the two groups (e.g., review in Zhang and Hayward 2001). Involuntary childlessness, however, may be associated with reduced well-being (Van Balen and Trimbos-Kember 1993).

Surprisingly little research in the United States has examined the impact of other aspects of childbearing history, especially high parity, on wellbeing. Census data from 1990 (U.S. Census Bureau 1990) indicate that the proportion of women aged 45 to 69 years who had five or more children was greater than that of those who had no children (Connidis 2001). This proportion continued to be substantial up to those aged 70 years and older, ranging from $13 \%$ to $19 \%$. Thus, the experience of women who have high parity deserves more attention and may be particularly important for African American women, whose fertility has always been higher than the national average. Kington et al. (1997) showed that women bearing six or more children had poorer selfrated health in later life, but further research on this association is lacking. 
Studies have shown that in the short term, pregnancy loss due to miscarriage or stillbirth leads to increased depressive symptoms among women (e.g., Hughes, Turton, and Evans 1999; Stirtzinger et al. 1999), while loss due to induced abortion can lead to reduced distress or to heightened grief, depending on the circumstances ("Induced Termination of Pregnancy" 1992; Zeanah et al. 1993). However, there have been almost no studies of the longer term impact that may be evident among women in later life.

In these research streams, racial and ethnic differences have been less frequently examined, a gap that needs to be filled given the persistent disparities in health outcomes and reproductive patterns across groups. The fertility of African American women is higher than that of White women, historically and currently. Although White and non-White fertility rose and fell in the baby bust and boom patterns, the latter's total fertility rate has always been slightly higher than that of the former (U.S. Department of Health, Education and Welfare 1977, Table 13). Data from the National Survey of Families and Households indicated that in 1976, among girls and women aged 15 to 44 years, 25.9\% of White women and $26.3 \%$ of Black women reported pregnancy losses (U.S. Department of Health and Human Services 1982).

\section{Theoretical Background}

We drew from life-course perspectives (Elder 1999) to examine the importance of childbearing and motherhood among the cohorts of women who were the mothers of the baby boom generation. The life-course perspective emphasizes first the importance of relating individual lives to their sociohistorical context, which for our analysis highlighted two features. First, the mothers of the baby boom experienced their childbearing careers at a time when fertility was higher compared with preceding and succeeding groups. Second, the life-course perspective highlights racial and ethnic disparities in the meaning and experience of motherhood, given the disparate social and familial histories of African Americans and Whites.

The present study included women who were born before 1939 and thus were the mothers of the baby boom cohort (born between 1946 and 1964). Especially among White women, social ideals of universal marriage, maternity, and middle-class, nuclear-family lifestyles with wage-earning husbands and caregiving mothers were prominent. Voluntarily childless women were very few in proportion. Although similar family ideologies may have existed among African American women in terms of the importance of motherhood and family, there were significant cultural and structural differences. Many aspects of child rearing among African Americans have been a community affair for various reasons, including the historically greater participation of African American mothers in the paid workforce, African kinship traditions, and the familial dislocations of slavery. Woman-centered, extended networks that Collins (1991) termed "othermothers," including grandmothers, other relatives, neighbors, and fictive kin, routinely took on child care responsibilities for one another's children.

These features led us to explicit consideration of racial disparities in the relation between childbearing history and older women's well-being. In the light of these differences, we considered, for example, whether White women with no children have more negative outcomes 
later in life compared with African American women, who may benefit from group motherhood norms to compensate for bearing no children.

Considering high parity, notwithstanding the comparatively high fertility in this cohort and the social climate endorsing motherhood, high parity could still be too much of a good thing. Theoretical perspectives from demography examine mechanisms such as "maternal depletion" among historical European or American populations (Alter et al. 2002), whereby frequent childbearing has a detrimental impact on women's health. Such discussion is lacking for current times, because industrialized nations are typically more concerned with below-replacement fertility and childlessness. The United States, however, has about the highest fertility among more developed nations, and older cohorts of women have more variation in the number of children born than younger cohorts. Furthermore, a strong research tradition in the United States (and other regions) has shown that having more children in a family is associated with poorer educational outcomes for children, because of "resource dilution," whereby parental time, attention, and finances must be more thinly spread among more children (Blake 1989). Hofferth (1984) showed that women in their 30s during the Great Depression who delayed childbearing and bore fewer children had better financial status than their counterparts. It is widely acknowledged that better financial status is associated with better health. In the present study, we examined whether high parity is negatively related to maternal well-being. There is little guidance from the literature as to what number of children might be optimal; therefore, in our study, we followed the lead of Kington et al. (1997) and considered six or more children to indicate high parity.

We also considered racial differences in these associations with little guidance from prior literature. On one hand, African American women with high parity may experience worse outcomes (compared with White women), given the lower resource levels of the community on average. Alternatively, the norms of group motherhood may protect women by spreading parenting tasks among the wider community.

In the same vein, although pregnancy loss is likely to be a stressful and painful experience for women of any racial or ethnic group, we considered whether the detrimental effects linger longer among African American women, who may have fewer resources to resist or recover from adverse life events; alternatively, the wider social networks characterizing the African American community may assist women of this group toward resilience in withstanding such losses.

The second key feature of the life-course perspective is the interconnectedness of individual and familial lives and roles. We drew from this feature to consider the role of the network of social ties and support within which African American and White mothers are embedded, which may mediate the relation between reproductive experiences and well-being in later life. The consideration of how social ties and support mediate between adverse events or experiences and health outcomes is a hallmark of the stress process model (Lin, Dean, and Ensel 1986; Pearlin et al. 1981). This framework therefore contributed to our examination of the impact of childbearing history on later-life health. Perceived social support has been shown to be of great importance in the relationship between a stressful event and the distress it generates and consequent mediation of the association between stressor and outcome (Wethington and Kessler 1986). In the present 
study, we focused on perceived social support as mediating the relationship between childbearing history and later-life well-being.

We considered potential pathways among different aspects of childbearing history, perceived social support, and later-life well-being. Most prior discussion of childlessness in the United States has considered the question of whether persons without children lack (or perceive a lack) of adequate social ties and support as they age and experience lower life satisfaction and poorer health outcomes. Alternatively, persons without children develop other associations to overcome the presumed deficits arising from the lack of parental role and ties with children and report no differences in wellbeing compared with their peers with children. In other words, the social ties and support networks of persons without children may be expected to play a key role in their well-being (Zhang and Hayward 2001). The goal of the present study was to replicate and extend these prior findings to specifically consider differences between African American and White women who have borne no children and whether the social support they perceive in later life plays a role in mediating any negative association observed for childless women in later-life well-being.

Concerning the potential stressor posed by high parity, most prior perspectives (e.g., the studies on maternal depletion and related mechanisms cited above) do not distinguish between shorter term negative outcomes of high parity and longer term consequences. Therefore, the implication we consider is that the stresses created by high parity continue later in life, perhaps through ongoing demands posed by children (rather than support received from them). In this situation, the perception of support received would help ameliorate strains posed by increased demands created by high parity.

Third, considering pregnancy loss, Corbet-Owen and Kruger's (2001) review shows that there are complex and multifaceted findings about the psychological aftermath of pregnancy loss, including long-term grief and mourning, depressive symptoms, major depressive disorder, anxiety, and somatic complaints. We therefore considered whether negative consequences of the stress linger later in life, whether social support mediates the association, and what racial differences, if any, exist.

Overall, therefore, we considered that different dimensions of childbearing history (bearing no children, high parity, or pregnancy loss) would elicit some form of social support among women in the shorter and longer terms. Those with no children seek other social ties; women experiencing pregnancy loss seek support in their grief, which may or may not be offered by members of their networks. Women with high parity may need or seek support to handle the strain of rearing many children, but prior literature does not provide clues on whether increased support is available. We therefore considered overall that women who did perceive support would report better health and fewer depressive symptoms than those who did not and that any negative impact of childbearing history on later life would be reduced for women who perceive adequate social support.

The literature regarding racial differences in the role of social support is mixed. In general, social support improves health outcomes among Whites and African Americans (Mutran, Reed, and Sudha 2001) and Haley et al. (1996) found that African American caregivers were more resilient 
than Whites to negative psychological health outcomes. The extended family system and strong family commitment among African Americans create a network that gives these families more strategies for survival and safety (Johnson 1995; Staples and Johnson 1993). However, compared with Whites, African Americans' larger and more diverse social and caregiving networks are associated with poorer health outcomes (Dilworth-Anderson, Williams, and Gibson 2002). It has been suggested that the networks in African American families place demands on women to the neglect of their personal needs (Kasuya, Polgar-Bailey, and Takeuchi 2000). Furthermore, in the African American community, health professionals, families, and friends tend to avoid discussions of losses because grief following pregnancy or infant loss is frequently considered insignificant by others (Van 2001). Therefore, in considering racial differences in the role of social support, we examined whether social support is less effective in mediating the negative impact of aspects of childbearing history on self-reported wellbeing in later life among African American compared with White women.

Furthermore, we hypothesized that the basic association between reproductive history and laterlife well-being would be more strongly negative among African American women compared with White women.

\section{Conceptual Framework of the Present Study}

In the present study, we examined the extent to which bearing no children, experiencing high parity, and pregnancy loss are detrimental to later-life health. The varying cultural histories of family and motherhood led us to consider how the associations differ among African American and White women. We also anticipated that the extent and effectiveness of social ties and social support in mediating the association would vary between the two racial groups. We adjusted for age, socioeconomic status, and physical-health variables in examining the relation between childbearing history and the two outcomes: subjective health perception and self-reported depressive symptoms.

\section{Hypotheses}

Specifically, we tested the following hypotheses:

Hypothesis 1: Women who bore no children, had high parity (more than six children), or experienced pregnancy loss will report themselves to have poorer health and more depressive symptoms later in life than women who had fewer (one to five) children and never experienced pregnancy loss.

Hypothesis 2: Race moderates these effects, in that the relations will be stronger for African American women than for White women.

Hypothesis 3: Social support mediates the association between childbearing history and women's well-being in later life. This effect will be stronger for White women than for African American women.

\section{Method}

Data Source 
This study used a large-scale, racially diverse database on community-dwelling older persons: the Atherosclerosis Risk in Communities study (The ARIC Investigators 1989), a federally funded, prospective epidemiologic study. Four U.S. communities-Forsyth County, North Carolina; Jackson County, Mississippi; suburban Minneapolis, Minnesota; and Washington County, Maryland - were selected, and approximately 4,000 adults aged 45 to 64 years were probabilistically selected from each, yielding a total sample size of 15,792. The sample from Jackson County represented its African American population, whereas those from the other three sites represented the racial mix of their populations. The proportion of African Americans in each study community was 24\% (Forsyth County), 48\% (Jackson County), 1\% (Minneapolis) and 4\% (Washington County).

Community respondents participated in four physical examinations three years apart and four waves of follow-up telephone interviews: the first from 1987 to 1989, the second from 1990 to 1992, the third from 1993 to 1995, and the fourth from 1996 to 1998. Those who had died in the interim were recorded. The response rate was $60 \%$ of those invited in visit 1 ; of those who participated in visit 1, 93\%, 86\%, and $80 \%$ returned for visits 2 , 3, and 4 , respectively. The study gathered in-depth details on medical histories and health status, reproductive histories, socioeconomic information, social support, and self-reported well-being (including health and depressive symptoms).

From the large initial sample, we selected female African American and White respondents aged 50 years and older at baseline who participated in visit 2, when the questions on depressive symptoms were asked. The resulting sample included 5,620 women (4,115 Whites and 1,505 African Americans). Analysis of self-rated health included women in waves 2, 3, and 4, for appropriate time sequencing of the dependent variables (self-rated health measured in each wave) and social support (measured in wave 2 only).

\section{Measures}

Two indicators of well-being were included as dependent variables: self-rated health and selfreported depressive symptoms.

Self-rated health was ascertained in all 4 waves of the study by the question "Compared to other people your age, would you say that your health is excellent, good, fair, or poor?” Responses were $0,1,2$, and 3 , respectively, with higher scores indicating poorer self-rated health. We include only waves 2,3 , and 4 to maintain clarity in the causal ordering of variables, because social support was measured only in wave 2.

Depressive symptomatology was obtained in wave 2, using 21 questions about mood, mental states, life satisfaction, and so on, which form the Vital Exhaustion/Depression Scale (Maastricht Questionnaire [MQ]; Appels, Falger, and Schouten 1993). The MQ is established as a measure of levels of psychological distress (Appels, Hoppener, and Mulder 1987; Appels and Mulder 1984, 1988, 1989, Pignalberi et al. 1998), capturing dimensions that include depression, exhaustion, and irritability. The responses are coded no $=0$, don't know $=1$, yes $=2$, so that the scale has a range of 0 to 42 , with higher scores indicating poorer psychological health. In a 
healthy population, the mean MQ score is 8.8 ( $S D=8.7$, median =6; Kop et al., 1996). Although the psychometric properties of this scale have not previously been examined for Whites compared with African Americans in the United States, we found Cronbach's $\alpha$ values of .86 for Whites and .85 for African Americans, indicating satisfactory internal consistency for both groups.

The main explanatory variables were those relating to childbearing history. Characteristics of women's childbearing history were obtained through reports of pregnancies and live births. The number of live births was categorized into three groups: women who had never borne children, those with one to five children, and those with six or more children. We select six or more children to indicate high parity for several reasons. First, prior literature (Kington et al. 1997) suggests that women with six or more children have poorer self-rated health in later life. Given the lack of wider examination of this association, we replicated the measurement of this prior study. Second, the figure of six or more children indicates approximately two standard deviations above the mean number of children for women of each race: In our data, African American women bore a mean of 4.40 children $(S D=2.81)$, whereas White women bore 3.06 children on average ( $S D=1.65)$. About $30 \%$ of African American women experienced high parity, whereas $7.5 \%$ of White women did so. Thus, using six or more children as an indicator of high parity has the advantages of replicating prior studies, indicating substantially higher than average childbearing, and including substantial proportions of women. Pregnancy loss was constructed from the difference between numbers of pregnancies and live births reported.

Demographic characteristics and socioeconomic and physical health status questions used as control variables in our analysis were included in the wave 1 questionnaire. These included age in years; education, defined as the highest grade of school completed, categorized into groups indicating those with less than high school, high school, general equivalency diplomas or vocational training, and some college; income, categorized as $1=$ less than $\$ 5,000,2=\$ 5,000$ to $\$ 7,000,3=\$ 8,000$ to $\$ 11,999,4=\$ 12,000$ to $\$ 15,999,5=\$ 16,000$ to $\$ 24,999,6=\$ 25,000$ to $\$ 34,999,6=\$ 35,000$ to $\$ 49,999$, and $7=\$ 50,000$ or more; and the presence and number of severe or chronic health conditions, an index of number of conditions based on self-reports of physician diagnoses of the presence of common major health conditions (hypertension, high blood cholesterol, heart attack, stroke, diabetes, cancer, chronic lung disease, and asthma).

A series of 18 questions were asked in wave 2 to obtain information on a wide range of items of perceived instrumental and emotional support. These included the availability of people to talk to when lonely, not feeling included by friends (reverse coded for consistent direction with other questions), having no one to give an objective view of how a respondent is handling problems (reverse coded), knowing someone to turn to when needing suggestions on how to deal with a personal problem, not often being invited to do things with others (reverse coded), having someone to help with chores if a respondent were sick, having someone to take a respondent to the doctor, having someone to look after a respondent's dwelling if she needed to go out of town for a short while, having no one to trust to give good financial advice (reverse coded), having difficulty finding someone to lend a car for a few hours (reverse coded), and having someone whose advice a respondent could really trust. The responses were coded "yes," "no," and "sometimes." We summed the responses to create a perceived-social-support measure, with higher scores indicating greater support. It included both instrumental and emotional support 
because preliminary analyses indicated that these submeasures were correlated and related in similar ways with the dependent variable. Cronbach's $\alpha$ values (.83 for Whites and .78 for African Americans) suggest satisfactory internal consistency for each race group for this measure.

\section{Analysis Plan}

Self-rated health was measured in each of the 4 waves. We took information only from waves 2, 3 , and 4 into account because including measures from the first wave would have confounded the time sequencing of the social-support measure, which was included only in wave 2 . The information from these three waves was analyzed as a cluster using generalized estimating equation regression techniques for ordinal data (as first described by Liang and Zeger 1986; conducted using PROC GENMOD in SAS version 8). Generalized estimating equation models extend the application of generalized linear modeling to analyze correlated data to get reasonable parameter estimates while accounting for the impact of the variance-covariance matrix for repeated measures. The method rests on assuming a specific number of time points at which respondents are measured, though every respondent does not have to be measured at each point (Hedeker and Gibbons 2005). The advantage of this approach is that it takes all the information available from longitudinal data into account while providing unbiased estimates.

Depressive symptoms were analyzed using ordinary least squares regression methods because they were measured only in wave 2 . The analysis therefore was cross-sectional.

For both analyses, we first considered the association between the childbearing-history variables and the outcomes net of control variables (model 1), adjusting for socioeconomic status and physical health. Then we added the social-support indicators (model 2) and observed how the associations changed to examine the mediating role of social support. We examined the conditioning role of racial group membership by analyzing African American and White women separately.

\section{Results}

Descriptive data are shown in Table 1 . A repeated-measures multivariate analysis of variance carried out using the SPSS generalized linear modeling procedure showed significant differences between African American and White women at each wave of the data. African American women consistently reported higher proportions than White women in the "fair" and "poor" categories and lower proportions in the "excellent" and "very good" categories. A $t$ test showed that African American women reported more depressive symptoms than White women. African American women also had a higher number of live births than White women. Chi-square analyses showed a higher proportion of African American than White women with six or more births (32.1\% vs. 8\%) and that more African American women experienced pregnancy loss. Proportions with no live births were equivalent across groups. This group of African American women reported significantly less perceived social support compared with the White respondents. They also had worse physical health and lower educational and income status than White women. 
Table 2 shows the bivariate associations between childbearing history and self-assessed health. The number of children and experiencing pregnancy loss were both significantly associated with increased depressive symptoms among African American women but not Whites. Having six or more children and experiencing pregnancy loss were associated with adverse self-reported health among both races of women. However, the associations appeared stronger among African American women than White women. Tables 3 and 4 present the multivariate analyses.

Table 3 examines associations with self-rated health as the dependent variable. Model 1 focused on the associations between childbearing-history variables, adjusting for socioeconomic status (education and family income), age, and physical health status. In model 2, perceived social support was entered to examine its mediating effect. Table 3 shows that having experienced pregnancy loss was associated with poorer self-rated health among African American women, but the effect was mediated by perceived social support. There was no significant association among White women. High parity (bearing six or more children) was associated with poorer self-rated health among African American women, and perceived social support did not mediate this association. Among White women, having borne no children appeared to be associated with improved self-rated health; entering social support into the model removed the association.

Table 4 examines depressive symptoms. For African American (but not for White) women, experiencing pregnancy loss was associated with more depressive symptoms (model 1); perceived social support reduced the association so that it was no longer significant. Bearing no children was associated with fewer depressive symptoms among African American women. Entering perceived social support into the model mediated this association. There was no significant association between childbearing history and depressive symptoms among White women. 
Table 1. Descriptive Characteristics and Ethnic Differences

\begin{tabular}{|c|c|c|c|c|c|}
\hline \multirow[b]{2}{*}{ Variable } & \multicolumn{2}{|c|}{ African Americans } & \multicolumn{2}{|c|}{ Whites } & \multirow[b]{2}{*}{$p$} \\
\hline & $M(S D)$ & $\%$ & $M(S D)$ & $\%$ & \\
\hline \multicolumn{6}{|l|}{ Self-rated health at wave 1} \\
\hline Excellent & & 15.3 & & 37.5 & \\
\hline Good & & 41.8 & & 49.2 & \\
\hline Fair & & 11.0 & & 34.8 & \\
\hline Poor & & 8.1 & & 2.4 & \\
\hline \multicolumn{6}{|l|}{ Self-rated health at wave 2} \\
\hline Excellent & & 13.3 & & 36.1 & \\
\hline Good & & 48.7 & & 49.9 & \\
\hline Fair & & 29.7 & & 11.5 & \\
\hline Poor & & 8.3 & & 2.6 & \\
\hline \multicolumn{6}{|l|}{ Self-rated health at wave 3} \\
\hline Excellent & & 10.0 & & 30.4 & \\
\hline Good & & 47.6 & & 53.1 & \\
\hline Fair & & 13.0 & & 33.2 & \\
\hline Poor & & 3.4 & & 9.2 & \\
\hline \multicolumn{6}{|l|}{ Self-rated health at wave 4} \\
\hline Excellent & & 8.0 & & 28.5 & \\
\hline Good & & 48.0 & & 54.3 & \\
\hline Fair & & 35.8 & & 14.1 & \\
\hline Poor & & 8.2 & & 3.1 & .000 \\
\hline Depressive symptoms & $14.67(9.11)$ & & $11.63(8.72)$ & & .000 \\
\hline \multicolumn{6}{|l|}{ Childbearing history } \\
\hline Number of live births & $4.40(2.81)$ & & $3.06(1.65)$ & & .000 \\
\hline \multicolumn{6}{|l|}{ Live births by category } \\
\hline No children & & 8.3 & & 8.3 & \\
\hline One to five children & & 61.4 & & 84.2 & \\
\hline Six or more children & & 30.3 & & 7.5 & .000 \\
\hline Number of pregnancy losses & $0.8(1.3)$ & & $0.5(1.1)$ & & .000 \\
\hline $\begin{array}{l}\text { Percentage with at least one } \\
\text { pregnancy lost }\end{array}$ & & 44 & & 32 & .000 \\
\hline \multicolumn{6}{|l|}{ Social support } \\
\hline Perceived social support scale & $38.00(5.30)$ & & $39.33(4.77)$ & & .000 \\
\hline \multicolumn{6}{|l|}{ Control variables } \\
\hline Number of health problems & $2.40(2.03)$ & & $1.85(1.99)$ & & .000 \\
\hline Mean age at baseline & $56.33(4.38)$ & & $56.63(4.29)$ & & \\
\hline Mean years of education & 12.6 & & 13.8 & & .000 \\
\hline Mean of income categories & $3.52(2.06)$ & & $5.93(1.79)$ & & .000 \\
\hline$n$ (women 50 and older) & 1,796 & & 4,400 & & \\
\hline
\end{tabular}


Table 2. Bivariate Relationships Between Reproductive History and Well-Being, by Race

Bivariate relationship between number of children and depressive symptoms (ANOVA)

\begin{tabular}{|c|c|c|c|c|c|c|}
\hline \multirow[b]{2}{*}{$\begin{array}{l}\text { Number } \\
\text { of children }\end{array}$} & \multicolumn{3}{|c|}{ African Americans } & \multicolumn{3}{|c|}{ Whites } \\
\hline & $\begin{array}{c}\text { Mean depressive } \\
\text { symptoms } \\
(S D)\end{array}$ & $F$ & $p$ & $\begin{array}{c}\text { Mean depressive } \\
\text { symptoms } \\
(S D)\end{array}$ & $F$ & $p$ \\
\hline No children & 12.4 & & & 10.9 & & \\
\hline One to five children & 14.4 & & & 11.6 & & \\
\hline Six or more children & 16.0 & 8.6 & .00 & 12.5 & 2.29 & .10 \\
\hline
\end{tabular}

Bivariate (Pearson) correlation between number of pregnancy losses and depressive symptoms

\begin{tabular}{llllll}
\hline & \multicolumn{2}{c}{ African Americans } & & \multicolumn{2}{c}{ Whites } \\
\cline { 2 - 3 } \cline { 5 - 6 } & $r$ & & & $r$ & .19 \\
\hline Number of pregnancy losses & .10 & .00 & & .02 & .19 \\
\hline
\end{tabular}

GEE parameter estimates of number of children on self-rated health

\begin{tabular}{|c|c|c|c|c|}
\hline & \multicolumn{2}{|c|}{ African Americans } & \multicolumn{2}{|l|}{ Whites } \\
\hline & Parameter estimate & $S E$ & Parameter estimate & $S E$ \\
\hline No live births ${ }^{\mathrm{a}}$ & .14 & .14 & -.16 & .13 \\
\hline Six or more live births ${ }^{a}$ & 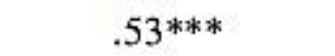 & 0.08 & $.23 *$ & .11 \\
\hline
\end{tabular}

GEE parameter estimates of the effect of pregnancy loss on self-rated health

\begin{tabular}{|c|c|c|c|c|}
\hline & \multicolumn{2}{|c|}{ African Americans } & \multicolumn{2}{|l|}{ Whites } \\
\hline & Parameter estimate & $S E$ & Parameter estimate & $S E$ \\
\hline Pregnancy loss & $.15 * *$ & .03 & $.09 * *$ & .03 \\
\hline
\end{tabular}

Note: $\mathrm{ANOVA}=$ analysis of variance; GEE = generalized estimating equation.

a. Reference category: one to five live births.

${ }^{*} p(z) \leq .05 .{ }^{* *} p(z) \leq .01 .{ }^{* * *} p(z) \leq .001$. 
Table 3. Generalized Estimating Equation Regression Analyses of Self-Rated Health on Childbearing-History Variables and Social Support for African American and White Women

\begin{tabular}{|c|c|c|c|c|c|c|c|c|}
\hline \multirow[b]{3}{*}{ Variable } & \multicolumn{4}{|c|}{ Af rican Americans $(n=1,796)$} & \multicolumn{4}{|c|}{ Whites $(n=4,400)$} \\
\hline & \multicolumn{2}{|c|}{ Model 1} & \multicolumn{2}{|c|}{ Model 2} & \multicolumn{2}{|c|}{ Model 1} & \multicolumn{2}{|c|}{ Model 2} \\
\hline & $\begin{array}{l}\text { Parameter } \\
\text { Estimate }\end{array}$ & $95 \% \mathrm{CI}$ & $\begin{array}{l}\text { Parameter } \\
\text { Estimate }\end{array}$ & $95 \% \mathrm{CI}$ & $\begin{array}{l}\text { Unstandardized } \\
\text { Coefficient }\end{array}$ & $S E$ & $\begin{array}{l}\text { Unstandardized } \\
\text { Coefficient }\end{array}$ & $S E$ \\
\hline \multicolumn{9}{|l|}{ Effect of pregnancy } \\
\hline loss & & & & & & & & \\
\hline Education & $0.06^{* * *}$ & 0.04 to 0.08 & $0.06 * *$ & 0.04 to 0.09 & $0.07 * *$ & 0.05 to 0.09 & $0.06^{* *}$ & 0.04 to 0.09 \\
\hline Income & $0.08^{* *}$ & 0.03 to 0.14 & $0.10 * *$ & 0.04 to 0.15 & $0.19 * *$ & 0.14 to 0.23 & $0.18^{* *}$ & 0.13 to 0.22 \\
\hline $\begin{array}{l}\text { Number of } \\
\text { heal th } \\
\text { problems }\end{array}$ & $-0.16^{* *}$ & -0.21 to -0.12 & $-0.17 * *$ & -0.22 to -0.12 & $-0.28 * *$ & -0.31 to -0.25 & $-0.27 * *$ & -0.31 to -0.23 \\
\hline Pregnancy loss & $-0.07 * *$ & -0.14 to -0.004 & -0.07 & -0.140 .11 & -0.06 & -0.14 to 0.004 & -0.03 & -0.11 to 0.04 \\
\hline Social support & & & $0.04 * *$ & 0.03 to 0.06 & & & $0.04 * *$ & 0.02 to 0.06 \\
\hline Constant & $-031^{\text {*** }}$ & -0.58 to -0.02 & $-1.95 * *$ & -2.66 to -1.24 & 0.26 & -0.08 to 0.61 & $-1.16^{* *}$ & -1.81 to -0.50 \\
\hline \multicolumn{9}{|l|}{$\begin{array}{l}\text { Effect of number } \\
\text { of children }\end{array}$} \\
\hline Education & $0.06^{* * *}$ & 0.03 to 0.08 & $0.06 * *$ & 0.04 to 0.08 & $0.07 * *$ & 0.05 to 0.09 & $0.06^{* *}$ & 0.04 to 0.09 \\
\hline Income & $0.09^{* *}$ & 0.04 to 0.14 & $0.09 * *$ & 0.05 to 0.15 & $0.18^{* *}$ & 0.14 to 0.22 & $0.17^{* *}$ & 0.13 to 0.22 \\
\hline $\begin{array}{l}\text { Number of } \\
\text { heal th } \\
\text { problems }\end{array}$ & $-0.17^{\text {*** }}$ & -0.21 to -0.12 & $-0.17 * *$ & -0.22 to -0.12 & $-0.29 * *$ & -0.33 to -0.26 & $-0.28^{* *}$ & -0.32 to -0.25 \\
\hline No children & -0.05 & -0.38 to 0.28 & -0.13 & -0.29 to 0.40 & $0.17 * *$ & 0.10 to 0.43 & 0.21 & -0.07 to 0.48 \\
\hline High parity & $-021^{\text {*** }}$ & -0.39 to -0.03 & $-0.20 * *$ & -0.41 to -0.00 & -0.10 & -0.35 to 0.15 & -0.09 & -0.35 to 0.18 \\
\hline Social support & & & $0.05 * *$ & 0.03 to 0.06 & & & $0.05^{* *}$ & 0.03 to 0.06 \\
\hline Constant & -021 & -0.50 to 0.08 & $-1.99 * *$ & -2.69 to -1.30 & 0.29 & -0.04 to 0.63 & $-1.30^{* *}$ & -1.94 to -0.67 \\
\hline
\end{tabular}

Note: $\mathrm{CI}=$ confidence interval.

$* * p(z) \leq .01$.

Table 4. Ordinary Least Squares Regression Analyses of Depressive Symptoms on ChildbearingHistory Variables and Social Support for African American and White Women

\begin{tabular}{|c|c|c|c|c|c|c|c|c|}
\hline \multirow[b]{3}{*}{ Variable } & \multicolumn{4}{|c|}{ African Americans $(n=1,796)$} & \multicolumn{4}{|c|}{ Whites $(n=4,400)$} \\
\hline & \multicolumn{2}{|c|}{ Model 1} & \multicolumn{2}{|c|}{ Model 2} & \multicolumn{2}{|c|}{ Model 1} & \multicolumn{2}{|c|}{ Model 2} \\
\hline & $\begin{array}{l}\text { Standardized } \\
\text { Coefficient }\end{array}$ & $S E$ & $\begin{array}{l}\text { Standardized } \\
\text { Coefficient }\end{array}$ & $S E$ & $\begin{array}{l}\text { Standardized } \\
\text { Coefficient }\end{array}$ & $S E$ & $\begin{array}{c}\text { Standardized } \\
\text { Coefficient }\end{array}$ & $S E$ \\
\hline \multicolumn{9}{|l|}{ Effect of pregnancy loss } \\
\hline Education & $-.15 * *$ & .06 & $-.10^{* *}$ & .06 & $-.15^{* *}$ & .04 & $-.13^{* *}$ & .04 \\
\hline Income & $-.07 * *$ & .15 & -.05 & .14 & $-.12^{* *}$ & .08 & $-.09 * *$ & .08 \\
\hline $\begin{array}{l}\text { Number of health } \\
\text { problems }\end{array}$ & $.19 * *$ & .13 & $.18^{* *}$ & .13 & $.16^{* *}$ & .08 & $.13^{* *}$ & .07 \\
\hline Pregnancy loss & $.06 * *$ & .18 & .04 & .19 & .02 & .13 & .01 & .13 \\
\hline Social support & & & $-.30^{* *}$ & .05 & & & $-.34 * *$ & .03 \\
\hline Constant & $17.10^{* * *}$ & 0.83 & $35.14^{* *}$ & 1.82 & $18.97^{* *}$ & 0.68 & $44.10^{* *}$ & 1.23 \\
\hline$F$ & $32.28 * *$ & & $53.89^{* *}$ & & $84.90^{* *}$ & & 191.61** & \\
\hline$R^{2}$ & .10 & & .18 & & .09 & & .22 & \\
\hline \multicolumn{9}{|l|}{$\begin{array}{l}\text { Effect of number } \\
\text { of children }\end{array}$} \\
\hline Education & $-.17 * *$ & .06 & $-.15^{* *}$ & .06 & $-.35^{* *}$ & .04 & $-.14 * *$ & .04 \\
\hline Income & $-.07 * *$ & .14 & -.12 & .14 & $-.62^{* *}$ & .08 & $-.08^{* *}$ & .08 \\
\hline $\begin{array}{l}\text { Number of health } \\
\text { problem }\end{array}$ & $.20 * *$ & .13 & $.16^{* *}$ & .14 & $.75^{* *}$ & .07 & $.13^{* *}$ & .07 \\
\hline No children & $-.05 * *$ & .89 & -.02 & .87 & -.50 & .50 & -.01 & .47 \\
\hline High parity & -.01 & .56 & .01 & .54 & .19 & .52 & .01 & .49 \\
\hline Social support & & & $-.30^{* *}$ & .05 & & & $-.37 * *$ & .03 \\
\hline Constant & $17.90 * *$ & 0.84 & $36.24^{* *}$ & 1.79 & $18.88^{* *}$ & 0.66 & $44.03^{* *}$ & 1.17 \\
\hline$F$ & $30.74 * *$ & & $49.63^{* *}$ & & $76.44 * *$ & & $178.06^{* *}$ & \\
\hline$R^{2}$ & .10 & & .19 & & .09 & & .22 & \\
\hline
\end{tabular}

*** $p \leq .01$. 


\section{Discussion}

In sum, variations in childbearing history appear to have a stronger impact on self-assessed health in later life among African American women in contrast to White women. However, the associations appear to some extent mediated by perceived social support. The analyses show that once social support is entered, there is no longer a significant effect of childbearing history variables (though the magnitude of the effect changes little). We also found that for African American but not White women, the impact of varying childbearing history suggests that having no live births is associated with fewer depressive symptoms and experiencing pregnancy loss with more depressive symptoms; both effects are mediated to some extent by social support.

These results provide partial support for our first hypothesis, that childbearing history would influence later-life well-being. Women who experienced pregnancy loss did report poorer selfrated health and more depressive symptoms later in life. Those with high parity reported poorer self-rated health only. As predicted by our second hypothesis, these effects were found among African American but not White women after adjusting for background factors. Third, we tested the hypothesis that perceived social support would mediate the impact of childbearing history on the outcomes, particularly among White women, but our findings did not support this argument. Among African American women, social support appeared to mediate most of the associations between pregnancy loss and bearing no children on depressive symptoms; however, perceived social support reduced the magnitude of the impact only of high parity on self-rated health. Among White women, there were few significant associations to mediate.

These findings suggest first that childbearing history continues to resonate in later life, particularly for African American women. Bearing many children and experiencing pregnancy loss were linked to perceptions of health. Depressive symptoms were less related to childbearing history and mediated by social support. In particular, regarding the wider literature on persons who have no children, our results showed that bearing no children not only had no detrimental effect but among African American women was associated with reduced depressive symptoms and among White women with improved self-rated health before controls for social support. In general, the association of having no children with better self-assessed wellbeing appears in line with the demographic trend toward lower fertility and increased proportion of childless women in U.S. society. Even among this cohort of women who were mothers of the baby boomers (i.e., having children at a time when economic and social factors supported higher fertility), having no children did not lead to deficits in well-being. In fact, high parity, as indicated by having six or more children, was in some situations associated with poorer outcomes.

Next, our findings on the role of perceived social support among African American women may cast light on the mechanism of othermother networks in African American culture (Collins 1991). First, among African American women, having six or more children was associated with poorer self-rated health prior to controlling for social support. This is in line with the idea that maternal depletion or resource dilution effects may be prevalent among this group, especially if social support is lacking. Social support influences the association, however, suggesting that the stresses of child rearing may be spread out over a group, perhaps among othermothers. Also, among African American women, having no live births is associated with lower levels of depressive symptoms, controlling for socioeconomic status. Social support removes the 
difference between such women and those with children, lending further support to the idea that women with children can seek social support to lighten the load of child rearing. Similarly, pregnancy loss is significantly related to depressive symptoms among African American women, which social support appears to mediate, again suggesting that the othermother mechanism may be operating. However, the fact that controlling for social support removes the significance of the childbearing history coefficients without substantial changes in their magnitudes suggests that meaningful mediation may not be occurring, necessitating further research to clarify these ideas. Among White women too, not bearing children appears associated with better self-assessed outcomes when social support is held constant, though no mechanism or social network comparable with othermother networks has been described for this group.

Our study has certain limitations. Although the database is advantageous in considering a diverse older population with adequate sample size and detailed investigation of reproductive history, because it was not designed to examine the specific issues studied here, some key concepts were not optimally measured. We had to use the number of live births rather than children raised (whether by birth, adoption, or fostering, the latter being notable in the African American community). Also, we considered pregnancy losses rather than infant or child death, experiences that may carry different kinds of painful meanings. However, as we suggested above, we thereby underestimated the numbers of children and child loss in families and thus provided conservative estimates of the associations. Additional variables on childbearing history, such as the timing of childbearing initiation, child spacing, and so on, were not included because of the lack of data; thus, a fuller consideration of the impact of timing of childbearing-history events suggested by the life-course perspective was not possible. Also, our analyses of depressive symptoms was cross-sectional, because social support was measured at the same time as depressive symptoms. As with all cross-sectional studies, this raises the issue of the likelihood that social support was elicited by respondents' depressive symptoms (though this possibility is less likely for perceived social support than for received support). Therefore, we suggest appropriate caution with regard to these findings and call for additional longitudinal research to clarify the associations. As discussed in the introductory sections, we have not been able to incorporate the important biological interlinks between reproductive experiences and health conditions more fully (beyond controlling for several health conditions), because health condition was measured only at the time of the baseline survey, and no retrospective information on status around the time of childbearing was collected. Finally, the sample of African American women, drawn from comparatively urbanized regions of specific southern counties, may not be entirely representative of their counterparts nationwide.

Notwithstanding these limitations, our study presents evidence on associations that have hitherto rarely been considered and suggests findings that future studies must replicate or address. Prior studies have rarely considered the impact of childbearing history on later-life health in a unified framework and have not considered these associations separately by race. The present findings contribute to the idea that research on the impact of childbearing history in later life must further develop a unified framework to study a more complete range of indicators and outcomes and must explicitly consider race and ethnicity, as urged by Jones (2001).

\section{References}


Alter, G., M. Oris, M. Neven, and G. Brostrom. 2002. Maternal Depletion and Mortality After the Childbearing Years in Nineteenth-Century East Belgium (Early-Life Conditions, Social Mobility, and Longevity Working Paper Series 2002, No. 71). Retrieved May 12, 2005, from http://www.indiana.edu/ pirt/ELC/WP/ELCpaper2002-07.pdf

Appels, A., P. R. Falger, and E. G. Schouten. 1993. "Vital Exhaustion as a Risk Indicator for Myocardial Infarction in Women.” Journal of Psychosomatic Research 37 (8): 881-90.

Appels, A., P. Hoppener, and P. Mulder. 1987. “A Questionnaire to Assess Premonitory Symptoms of Myocardial Infarction.” International Journal of Cardiology 17 (1): 15-24.

Appels, A. and P. Mulder. 1984. "Imminent Myocardial Infarction: A Psychological Study." Journal of Human Stress 10 (3): 129-34.

- 1988. "Excess Fatigue as a Precursor of Myocardial Infarction.” European Heart Journal 9 (7): 758-64.

. 1989. “Fatigue and Heart Disease. The Association Between 'Vital Exhaustion’ and Past, Present and Future Coronary Heart Disease.” Journal of Psychosomatic Research 33 (6): 727-38.

The ARIC Investigators. 1989. "The Atherosclerosis Risk in Communities Study: Design and Objectives.” American Journal of Epidemiology 129 (4): 687-702.

Benyamini,Y. and E. Idler. 1999. "Community Studies Reporting Association Between SelfRated Health and Mortality: Additional Studies 1995 to 1998.” Research on Aging 21:392-401.

Blackwell, D. L., M. D. Hayward, and E. M. Crimmins. 2001. "Does Childhood Health Affect Chronic Morbidity in Later Life?” Social Science \& Medicine 52:1269-84.

Blake, J. 1989. Family Size and Achievement. Berkeley: University of California Press.

Cameron, N. and E. W. Demerath. 2002. "Critical Periods in Human Growth and Their Relationship to Diseases of Aging.” American Journal of Physical Anthropology Suppl 35:159-84.

Collins, P. H. 1991. “The Meaning of Motherhood in Black Culture and Black Mother- Daughter Relationships.” Pp. 42-60 in Double Stitch: Black Women Write About Mothers and Daughters, edited by P. Bell-Scott, B. Guy-Sheftall, J. Jones Royster, J. Sims-Wood, M. DeCosta-Willis, and L. Fultz. Boston: Beacon.

Connidis, I. A. 2001. Family Ties and Aging. Thousand Oaks, CA: Sage. 
Corbet-Owen, C. and L.-M. Kruger. 2001. "The Health System and Emotional Care: Validating the Many Meanings of Spontaneous Pregnancy Loss.” Families, Systems \& Health 19 (4): 41126.

Dilworth-Anderson, P., I. C. Williams, and B. Gibson. 2002. "Issues of Race, Ethnicity and Culture in Caregiving Research: A 20 Year Review.” The Gerontologist 42:237-72.

Elder, G. H., Jr. 1999. Children of the Great Depression: Social Change in Life Experience. Boulder, CO: Westview Press.

Haley,W. E., D. L. Roth, M. I. Coleton, G. R. Ford, C.A. West, R. P. Collins, and T. L. Isobe. 1996. "Appraisal, Coping, and Social Support as Mediators of Well-Being in Black and White Family Caregivers of Patients With Alzheimer's Disease.” Journal of Consulting and Clinical Psychology 64:121-29.

Hedeker, D. and R. D. Gibbons. 2005. Applied Longitudinal Data Analysis. Hoboken, NJ: John Wiley.

Hofferth, S. L. 1984. "Long Term Economic Consequences for Women of Delayed Childbearing and Reduced Family Size.” Demography 21:140-49.

Hughes, P. M., P. Turton, and C. D. Evans. 1999. "Stillbirth as Risk Factor for Depression and Anxiety in the Subsequent Pregnancy: Cohort Study.” BMJ 318 (7200): 1721-24.

Idler, E. L. and Y. Benyamini. 1997. "Self-Rated Health and Mortality: A Review of TwentySeven Community Studies.” Journal of Health and Social Behavior 38 (1): 21-37.

"Induced Termination of Pregnancy Before and After Roe v Wade. Trends in the Mortality and Morbidity of Women. Council on Scientific Affairs, American Medical Association.” 1992. JAMA 268 (22): 3231-39.

Johnson, C. 1995. "Cultural Diversity in the Late-Life Family.” Pp. 307-30 in Handbook of Aging and the Family, edited by R. Blieszner and V. H. Bedford. Westport, CT: Greenwood.

Jones, C. P. 2001. “Invited Commentary: 'Race,' Racism and the Practice of Epidemiology.” American Journal of Epidemiology 154 (4): 299-304.

Kasuya, R., P. Polgar-Bailey, and R. Takeuchi. 2000. "Caregiver Burden and Burnout: A Guide for Primary Care Physicians.” Postgraduate Medicine 108:119-28.

Kington, R., L. Lillard, and J. Rogowski. 1997. "Reproductive History, Socioeconomic Status and Self-Reported Health Status of Women Aged 50 Years and Older.” American Journal of Public Health 87 (1): 33-37. 
Kop, W. J., A. P. W. M. Appels, C. F. Mendes de Leon, and F. W. Bar. 1996. "The Relationship Between Severity of Coronary Artery Disease and Vital Exhaustion.” Journal of Psychosomatic Research 40 (4): 397-405.

Liang, K.-Y. and S. L. Zeger. 1986. “Longitudinal Data Analysis Using Generalized Linear Models.” Biometrika 73 (1): 13-22.

Lin N., A. Dean, and W. M. Ensel. 1986. Social Support, Life Events and Depression. Orlando, FL: Academic Press.

Mutran E. J., P. Reed, and S. Sudha. 2001. "Social Support: Clarifying the Construct With Application for Minority Populations.” Journal of Mental Health and Aging 7:67-78. Pearlin, L. I., E. G. Menaghan, M. A. Lieberman, and J. T. Mullan. 1981. “The Stress Process.” Journal of Health and Social Behavior 22:337-56.

Pignalberi, C., G. Patti, C. Chimenti, V. Pasceri, and A. Maseri. 1998. "Role of Different Determinants of Psychological Distress in Acute Coronary Syndromes." Journal of the American College of Cardiology 32 (3): 613-19.

Staples, R. and L. Johnson. 1993. Black Families at the Crossroads: Challenges and Prospects. San Francisco, CA: Jossey-Bass.

Stirtzinger, R. M., G. E. Robinson, D. E. Stewart, and E. Ralevski. 1999. "Parameters of Grieving in Spontaneous Abortion.” International Journal of Psychiatric Medicine 29 (2): 23549.

U.S. Census Bureau. 1990. “Children Ever Born by Parity, Race, Age, Marital Status and Nativity of Women: April 1990” (CPH-L-194). Retrieved May 14, 2002 from http://www.census.gov/Press-Release/cb96-182.html

U.S. Department of Health, Education, and Welfare. 1977. "Trends in Fertility in the United States” (DHEW Publication No. HRA 78-1906). Data from the National Vital Statistics System Series 21, Number 28. Hyattsville, MD: National Center for Health Statistics.

U.S. Department of Health and Human Services. 1982. "Reproductive Impairments Among Married Couples” (DHHS Publication No. PHS 83-1987). Data from the National Survey of Family Growth Series 23, No. 11. Retrieved December 15, 2002, from http://www.cdc.gov/nchs/data/series/sr_23/sr23_011.pdf

Van, P. 2001. "Breaking the Silence of African American Women: Healing After Pregnancy Loss.” Health Care for Women International 22:229-243.

Van Balen, F. and T. C. Trimbos-Kemper. 1993. "Long-Term Infertile Couples: A Study of Their Well-Being.” Journal of Psychosomatic Obstetrics and Gynaecology 14 (Suppl.): 53-60. 
Wethington, E. and R. C. Kessler. 1986. "Perceived Support, Received Support and Adjustment to Stressful Life Events.” Journal of Health and Social Behavior 27 (1): 78-89.

Zeanah, C. H., J. V. Dailey, M. J. Rosenblatt, and D. N. Saller, Jr. 1993. “Do Women Grieve After Terminating Pregnancies Because of Fetal Anomalies? A Controlled Investigation.” Obstetrics and Gynecology 82 (2): 270-75.

Zhang, Z. and M. D. Hayward. 2001. "Childlessness and the Psychological Well-Being of Older Persons.” Journals of Gerontology 56B (5): S311-21.

S. Sudha is on the faculty of the Department of Human Development and Family Studies at the University of North Carolina at Greensboro. Her research interests focus on how family contexts and processes influence the well-being of different family members in diverse racial and ethnic and cultural environments. She has conducted research on gender differences in the association between marital status and kinship ties and self-rated health among seniors in southern India, how socioeconomic development and cultural changes are related to the rise of son preference in a southern Indian community, and how experiences of and attitudes toward domestic violence influence the uptake of reproductive health services among southern Indian women.

Elizabeth J. Mutran is a professor emerita in the Department of Health Education and Health Behavior in the School of Public Health at the University of North Carolina at Chapel Hill. She remains active in the Institute on Aging at the university. Her interest in health disparities and ethnic differences formed a continual thread throughout her career. In the past few years, she has published in the area of identity and the grandparent role and on racial differences in satisfaction with assisted living.

Ishan C. Williams is a research assistant professor in the School of Nursing at the University of Virginia. Her interests relate to family caregivers of older adults with chronic illnesses and the health and well-being of minority family caregivers. She focuses on understanding the health care needs of older adults and their caregivers within social, cultural, and geographical contexts. Her recent research includes "Emotional Health of Black and White Dementia Caregivers: A Contextual Examination” (The Journals of Gerontology Series B: Psychological Sciences and Social Sciences, 2005).

Chirayath Suchindran is a mathematical demographer and one of the Carolina Population Center's statistical advisors. His past U.S. research includes comparing methods of natural family planning; interrelationships of fertility, marital disruption, and remarriage; marital events and the life course in middle and older ages; the consequences of childlessness; and effects on birth weight of work during pregnancy. He has examined infant mortality determinants in the Near East and the effects of community factors on Mexican fertility. He is developing models to analyze child spacing, contraceptive acceptance, and breast-feeding effects on postpartum amenorrhea and conception rates in developing countries. He is investigating the age at which U.S. women complete childbearing, North Carolina infant mortality, and biosocial factors in teenage behavior. He serves as a member of the Carolina Population Center's Training Committee. He directs a statistical demography training program in biostatistics and teaches primary population courses. Dr. Suchindran recently completed a two-year term as president of 
the Triangle Area Population Society. His current methodological and research interests include developing methods for analyzing spatial temporal demographic data as well as partial-birth history data. His current research projects include the behavioral dynamics of HIV/AIDS in developing countries and the association between exposure to violence and partner violencerelated outcomes among adolescents. 